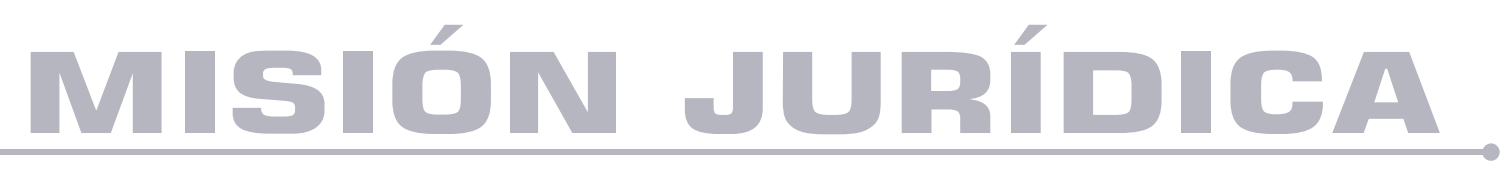

\title{
El feminicidio en México: la obligación de combatirlo y la responsabilidad objetiva del poder ejecutivo federal y de los gobiernos estatales
}

Feminicide in Mexico: the obligation to combat it and the Strict

Liability of the Federal Executive Branch and the State Governments

Autor: Xelha Montserrat Brito Jaime

DOI: https://doi.org/10.25058/1794600X.1949

\footnotetext{
Ś MISIÓN JURÍDICA A
} 


\title{
El feminicidio en México: la obligación de combatirlo y la responsabilidad objetiva del poder ejecutivo federal y de los gobiernos estatales*
}

\author{
Feminicide in Mexico: the obligation to combat it and the Strict \\ Liability of the Federal Executive Branch and \\ the State Governments \\ Femicídio no México: a obrigação de combatê-lo e a responsa- \\ bilidade objetiva do Poder Executivo federal e \\ dos governos estaduais
}

Xelha Montserrat Brito Jaime
xmbj19@gmail.com

Fecha de recepción: 1 de julio de 2020

Fecha de revisión: 6 de julio de 2020

Fecha de aceptación: 30 de julio de 2020

\section{RESUMEN}

Ante el constante incremento de violencia feminicida, el Estado mexicano está obligado a implementar enérgicamente todas las medidas necesarias para combatir este fenómeno delictivo. Una de las principales demandas estriba en la falta de información concreta para el diseño de adecuadas políticas públicas. En esa tesitura, el presente artículo tiene como finalidad indicar algunas de las obligaciones compartidas entre los gobiernos estatales y el gobierno federal, tales como: 1) brindar y recabar información útil respecto a la incidencia delictiva sistematizada, e

\footnotetext{
* Artículo de investigación científica que presenta algunos argumentos motivados por el ejercicio de dictaminación de una proposición de punto de acuerdo presentado en la Cámara Alta mexicana en materia de feminicidio. Se omite la referencia completa del mencionado punto de acuerdo en virtud a que el mismo es propiedad del senador que lo realizó; sin embargo, se precisa que este tuvo como propósito exhortar a las entidades federativas mexicanas que reportaran las medidas que han implementado, con base en datos estadísticos, para prevenir y erradicar el feminicidio. En el presente artículo se desarrollan algunas reflexiones en base a datos estadísticos recientes, recopilados desde entes gubernamentales cuyos datos son verificables en las páginas web oficiales referidas en cada ocasión.

a. Licenciada en Derecho por la Universidad Nacional Autónoma de México (UNAM). Ha sido asistente de investigación en el Instituto de Investigaciones Jurídicas de la UNAM, colaboradora en la Revista de la Facultad de Derecho de México y practicante judicial en la Suprema Corte de Justicia de la Nación. Actualmente es asesora parlamentaria en la Cámara de Senadores, autora de diversos artículos publicados en México y en el extranjero y, ponente en foros nacionales e internacionales. Presidenta del Foro de Jóvenes Administrativistas de la Asociación Mexicana de Derecho Administrativo. ORCID: 0000-0001-8361-446X.
} 
interpretable; y 2) con la información obtenida, diseñar políticas públicas evaluables e idóneas para combatir la violencia de género y su expresión más grave: el feminicidio.

Al tomar como marco referencial los derechos humanos en el presente estudio, se parte del contexto actual que sufren las mujeres en México, con cifras oficiales presentadas por entes públicos nacionales e internacionales. Posteriormente, se desarrollan las obligaciones convencionales del Estado mexicano y las referidas constitucionalmente para todas las autoridades y todos los niveles de gobierno; finalmente, se menciona el deber de coordinación y coadyuvancia en materia de seguridad pública entre el gobierno federal y las entidades federativas. Así, se esboza la siguiente hipótesis: el incumplimiento de estas obligaciones deriva en responsabilidades objetivas, por daños que resultan en violaciones a derechos humanos y atentados persistentes e irreparables contra la dignidad de mujeres, niñas y adolescentes.

\section{PALABRAS CLAVE:}

Feminicidio; derechos humanos; violencia contra las mujeres; responsabilidad del Estado; responsabilidad objetiva; Federación; entidades federativas; Constitución.

\begin{abstract}
:
Faced with the constant increase in feminicide violence, the Mexican State is obliged to vigorously implement all the necessary measures to fight this criminal phenomenon. One of the main demands lies in the lack of concrete information for the design of adequate public policies. At his juncture, the purpose of this article is to indicate the obligations that the state and federal governments have, such as: 1) to provide and collect useful information regarding the systematized and interpretable crime incidence and 2) to design with the gathered information suitable public policies to combat gender violence and its most serious expression: feminicide. Taking Human Rights as the frame of reference in this study, we start from the current context suffered by women in Mexico with official figures presented by national and international public entities. Subsequently, the conventional obligations of the Mexican State are developed, as well as the constitutional ones, which address all the authorities at all levels of government. Finally, the
\end{abstract}

duties of coordination and assistance in matters of public security between the federal government and the federal entities are outlined. Considering the mentioned references, this research concludes that the breach of these obligations derives in objective responsibilities, for damages that result in human rights violations and persistent and irreparable attacks against the dignity of women, girls and adolescents.

\section{KEY WORDS}

Feminicide, Human Rights, violence against women, responsibility of the State, strict liability, Federation, federal entities, Constitution.

\section{RESUMO}

Dado o constante aumento da violência feminicida, o Estado mexicano se vê obrigado a implementar vigorosamente todas as medidas necessárias para combater este fenômeno criminoso. Uma das principais demandas é a falta de informações concretas para o desenho de políticas públicas adequadas. Nesse contexto, este artigo tem como objetivo indicar algumas das obrigações compartilhadas entre os governos estaduais e o governo federal, tais como: 1) fornecer e coletar informações úteis sobre a incidência sistematizada e interpretável de crimes; e 2) com as informações obtidas, desenhar políticas públicas avaliáveis e adequadas para o enfrentamento da violência de gênero e sua expressão mais grave: o feminicídio.

Tomando os direitos humanos como referencial neste estudo, partimos do contexto atual vivido pelas mulheres no México, com cifras oficiais apresentadas por entidades públicas nacionais e internacionais. Posteriormente, são desenvolvidas as obrigações convencionais do Estado mexicano e aquelas a que se refere constitucionalmente todas as autoridades e todos os níveis de governo; por fim, menciona-se o dever de coordenação e assessoria em matéria de segurança pública entre o governo federal e os estados. Assim, traça-se a seguinte hipótese: o descumprimento dessas obrigações resulta em responsabilidade objetiva, por danos que resultem em violações de direitos humanos e ataques persistentes e irreparáveis à dignidade da mulher, das meninas e dos adolescentes.

\section{PALAVRAS-CHAVES}


Feminicídio; direitos humanos; violência contra as mulheres; Responsabilidade estatal; responsabilidade estrita; Federação; entes federativos; Constituição.

\section{INTRODUCCIÓN}

El presente artículo tiene como objetivo enfatizar las obligaciones que tienen tanto los gobiernos estatales como el gobierno federal, consistentes en: 1) brindar y recabar información de calidad de incidencia delictiva sistematizada, e interpretable; y, 2) con esa información, diseñar políticas públicas evaluables e idóneas para combatir la violencia de género y su expresión más grave: el feminicidio. En ese sentido, la omisión de dichas obligaciones trae como consecuencia responsabilidades de carácter objetivo por el incremento en las cifras de este acto delictivo.

Para llegar a dicho término, el hilo conductor son los derechos humanos, de las mujeres, niñas $\mathrm{y}$ adolescentes, a una vida libre de violencia, por lo que se parte del contexto actual en México con datos oficiales de instancias gubernamentales. Posteriormente, se enmarcan las obligaciones del Estado mexicano en materia de derechos humanos con la respectiva acotación a los derechos de las mujeres, niñas y adolescentes para pasar a esbozar el deber de coordinación que prevén las leyes especiales. Este deber de coordinación se origina en la Federación y las entidades federativas, con lo que se concluye que, efectivamente, es una obligación compartida llevar a cabo medidas tendientes a la erradicación de todas las formas de violencia contra la mujer, y especialmente, la erradicación de la violencia feminicida, cuyo incumplimiento se traduce en responsabilidades objetivas.

\section{METODOLOGÍA}

Con ayuda del método analítico, primero se hace una recopilación cuantitativa de datos oficiales para pasar a una conclusión cualitativa que destaca la gravedad del contexto de violencia contra las mujeres, adolescentes y niñas. Luego, se realizó una búsqueda en la legislación, empezando por el marco convencional en materia de derechos humanos para dejar claras las obligaciones del Estado mexicano, después las contenidas en el marco constitucional $y$, finalmente, la obligación de coordinación establecida en leyes secundarias, para concluir que el incumplimiento de las obligaciones descritas se traduce en responsabilidades objetivas.

\section{RESULTADOS}

Existe un marco jurídico que va desde el nivel convencional hasta la legislación secundaria mexicana, que precisa el deber de coordinación del gobierno federal y de las entidades federativas para erradicar toda forma de violencia contra las mujeres. El incumplimiento de dicho marco normativo se convierte en responsabilidad objetiva de ambos niveles de gobierno y se traduce en violaciones graves a los derechos humanos de las niñas, adolescentes y mujeres del país.

\section{Contexto actual sobre violencia contra las mujeres. \\ En México, según la Comisión Nacional de} Derechos Humanos en la Recomendación General 40/2019, el 66.1\% de las mujeres de 15 años y más han enfrentado al menos un incidente de violencia por parte de cualquier agresor en su vida; en el caso de las mujeres con pareja la prevalencia asciende al $43.9 \% \mathrm{y}$, en general, el $34.3 \%$ de las mujeres señaló haber sido víctima de violencia sexual en espacios públicos o comunitarios, resultado de la Encuesta Nacional sobre la Dinámica de las Relaciones en los Hogares (ENDIREH) realizada en 2016 (Comisión Nacional de DDHH, 2019).

Asimismo, respecto a los delitos perpetrados contra niñas y adolescentes en el periodo 2015 2018, ONU Mujeres, elaboró el estudio "Violencia y feminicidio de niñas y adolescentes en México", con datos proporcionados por el Secretariado Ejecutivo del Sistema Nacional de Seguridad Pública (SESNSP), órgano administrativo desconcentrado de la Secretaría de Gobernación que coordina y define las políticas en materia de seguridad pública. En dicho informe se señala que dentro del periodo referido se registraron 194 feminicidios de niñas y adolescentes, 3,044 casos de corrupción de menores, 671 homicidios dolosos, 12,545 lesiones dolosas, 201 casos de tráfico de menores y 427 casos de trata de personas (ONU, 2018).

A pesar de lo alarmantes que son estas cifras, el 2019 fue aún peor, de modo que los periódicos de mayor circulación en México destacaron en sus portadas la noticia en la que oficialmente, el 
año 2019 se catalogaba como el más violento ${ }^{1}$. Según cifras proporcionadas por el órgano administrativo referido, desde el año 2015 al 2019 , el femicidio ha ido en aumento a nivel nacional, siendo que en 2015 se reportaron 411, 602 en 2016, 741 en 2017, 891 en 2018 y 976 en 2019 presuntos delitos de este tipo (Sistema Nacional de Seguridad Pública -SNSP, 2019).

A nivel nacional, de los feminicidios reportados en 2019 en el país, el estado de Veracruz ocupó el primer lugar con 157 delitos de feminicidio, seguido por el Estado de México con 122; Ciudad de México con 68; Nuevo León con 67 y Puebla con 58. Estas fueron las entidades federativas con la mayor cantidad de casos de feminicidios reportados (SNSP, p. 15).

Las cifras presentadas son muestra de la evidente necesidad de implementación de mecanismos eficientes que atiendan el problema de fondo y con perspectiva integral, siendo la vía jurídica solo una de varias que debe considerar el Estado. Por ello, resulta impostergable admitir que es deber de cada autoridad priorizar en su agenda a la atención de esta problemática; además, es crucial establecer los lineamientos que cada nivel de gobierno debe seguir para coordinadamente proceder a la ejecución de políticas públicas evaluables. De lo contrario, se vislumbra el caos y la ineficiencia, que se traduce en responsabilidades por violaciones sistemáticas al derecho a la vida e integridad corporal de mujeres, niñas y adolescentes, por omisiones atribuibles al Estado.

Sin embargo, cada entidad federativa tiene características especiales por lo que el contexto de violencia se presenta de forma diferenciada. Ahí radica la importancia de que sean dichas entidades las que proporcionen información y datos estadísticos reales a las instancias de seguridad pública encargadas de concentrar e interpretar los datos, lo cual constituye la base para el diseño de políticas públicas concretas en

\footnotetext{
1. Ejemplos:

"Es oficial: el 2019 fue el año más violento". El Universal, 20 de enero de 2020. (Espino, 2020).

CNN en español (2020): "Es oficial: el 2019 ha sido (sic) el año más violento" (21 de enero de 2020).

"2019 se convierte en el año más violento en la historia reciente de México". El País, 22 de enero de 2020. (Beauregard, 2020).

"2019, el más violento para las mexicanas". La Jornada, 26 de enero de 2020. (Martínez, 2020).
}

aras de prevenir y erradicar la comisión de este ilícito.

\section{Contexto actual sobre violencia contra las mujeres.}

\section{a) Obligaciones establecidas en tratados} internacionales.

El marco convencional que contiene las obligaciones del Estado mexicano referentes a la erradicación de toda forma de violencia contra las mujeres en el ámbito regional deriva de la Convención Americana sobre Derechos Humanos (CADH) o Pacto de San José ${ }^{2}$ que, conjuntamente con las disposiciones especiales de la materia, consagran el derecho de las mujeres a acceder a la justicia de forma sencilla y eficaz. Además, el mecanismo debe contar con las debidas garantías cuando se denuncian hechos de violencia, y en respuesta, el Estado tiene la obligación de actuar con la debida diligencia para prevenir, investigar, sancionar y reparar.

Así mismo, la Convención Interamericana para Prevenir, Sancionar y Erradicar la Violencia Contra la Mujer "Convención de Belém do Pará", adoptada el 9 de junio de $1994^{3}$, estableció por primera vez el derecho de las mujeres a vivir una vida libre de violencia e instituyó el concepto de violencia contra la mujer en su primer artículo, entendiéndose como "cualquier acción o conducta, basada en su género, que cause muerte, daño o sufrimiento físico, sexual o psicológico a la mujer, tanto en el ámbito público como en el privado".

Por su parte, la Convención de Belém do Pará establece que los Estados convienen adoptar progresivamente las medidas pertinentes para garantizar el derecho de las mujeres al acceso a la justicia en casos de violencia, para lo cual, el artículo 8 determina que los Estados Partes convienen en adoptar progresivamente medidas específicas, inclusive programas para fomentar la educación y capacitación del personal en la administración de justicia, policial y demás funcionarios encargados de la aplicación de la ley, así como del personal a cuyo cargo esté la implementación de las políticas de prevención, sanción y eliminación de la violencia contra la mujer.

2. Ratificada por México en mayo de 1981

3. México ratificó este instrumento internacional de naturaleza jurídica vinculante el 19 de junio 1998. 
En el mismo sentido, dispone que es un compromiso de los Estados garantizar la investigación y recopilación de estadísticas y demás información pertinente sobre las causas, consecuencias y frecuencia de la violencia contra la mujer, con el fin de evaluar la eficacia de las medidas para prevenir, sancionar y eliminar la violencia contra la mujer y de formular y aplicar los cambios que sean necesarios, entre otras disposiciones.

Este segundo aspecto es destacable, ya que, como se mencionó, el recabar los datos estadísticos de manera puntual y bajo estándares óptimos, así como su debida interpretación, contribuyen a garantizar el derecho de las mujeres a una vida libre de violencia, al permitir que las medidas se adopten progresivamente con miras a la erradicación de toda conducta que vulnere este derecho, lo que se traduce en la realización de acciones adecuadas para combatir el feminicidio.

Aunado a lo anterior, en 2009, la Corte Interamericana de Derechos Humanos (CIDH) declaró la responsabilidad internacional del Estado mexicano en la sentencia del caso conocido como "Campo algodonero vs. México". Para la comunidad interamericana, el fallo tiene especial trascendencia al ser la primera vez que la Corte examinó una situación estructural de violencia contra las mujeres basada en su género.

En términos generales, esta responsabilidad internacional del Estado fue declarada en dos sentidos: en primer lugar, por violación a los derechos sustantivos a la vida (artículo 4 de la $\mathrm{CADH}$ ), el derecho a la integridad personal (artículo 5 de la misma Convención) y el derecho a la libertad personal (artículo 7). Dichas violaciones fueron interpretadas en relación con la obligación del deber de respeto que impone el artículo $1^{\circ}$ del Pacto de San José, así como en relación con el deber de no discriminación contenido en el artículo 1.1. (CIDH, 2009).

En segundo lugar, el Estado mexicano fue declarado responsable (aunque indirectamente, según analiza Gloria Fernández Arribas) de los crímenes cometidos contra estas mujeres, por no adoptar las medidas adecuadas para impedir la comisión de dichos crímenes en función del deber de garantía que impone el artículo 1 de la Convención (Fernández, 2013), es decir, omitió realizar todas las acciones para evitar que se perpetuaran los crímenes $y$, de igual forma, incumplió su deber de investigar $\mathrm{y}$, con ello, de garantizar los derechos enunciados con anterioridad.

Como consecuencia de dicha sentencia, en México se puso en marcha la maquinaria legislativa y jurisdiccional para incorporar, en las disposiciones de derecho interno, protocolos con perspectiva de género en todos los órdenes de gobierno $\mathrm{y}$, se reformó el Capítulo $\mathrm{V}$ del Título Decimonoveno "Delitos contra la vida y la integridad corporal", artículo 325, del Código Penal Federal, para tipificar el delito de feminicidio (Diario Oficial de la Federación, 2014). Posteriormente, fueron reformados diversos códigos penales locales, así como la Ley General de Acceso de las Mujeres a una Vida Libre de Violencia, promulgada con anterioridad, en febrero de 2007.

En este sentido, es evidente que los derechos de las mujeres, así como el combate a la violencia de género, se circunscriben a las obligaciones en materia de derechos humanos que tiene el Estado mexicano. No obstante, es menester ser específicos en cuanto a las autoridades en quienes recae dicha obligación, ya que, hablar de Estado mexicano, se hace alusión a un ente abstracto, por lo que resulta importante hacer un ejercicio de búsqueda en la legislación interna para definir con precisión los órganos e instituciones del Estado que tiene la obligación de cumplimiento.

\section{b) Disposiciones de derecho interno}

La lectura sistemática del artículo $1^{\circ}$ con el 133 de la Carta Magna mexicana permite destacar que todas las autoridades, en el ámbito de sus competencias deben promover, respetar, proteger y garantizar los derechos humanos de conformidad con los principios de universalidad, interdependencia, indivisibilidad y progresividad. Derivado del deber de garantizar, tienen las obligaciones de prevenir, investigar, sancionar y reparar las violaciones a los derechos humanos, en los términos que establezca la ley. Asimismo, el parámetro de regularidad constitucional en materia de derechos humanos se ve vinculado por la legislación nacional, así como por los tratados internacionales de los que México es parte, por lo que la Constitución, las leyes del Congreso de la Unión que emanen de ella y, todos los tratados que estén de acuerdo con la misma, celebrados y que se celebren por el presidente de la República, con aprobación del Senado, son la Ley Suprema de toda la Unión (Diario Oficial de la Federación, 2021). 
De esta forma, la Constitución establece las obligaciones generales y específicas en materia de derechos humanos que, aplicadas al tema de mérito, se trata de los derechos de las mujeres, niñas y adolescentes. Estas obligaciones las deben cumplir todas las autoridades de todos los niveles de gobierno (municipal, estatal y federal). Igualmente, su ámbito de competencia se circunscribe transversalmente, es decir, a las autoridades pertenecientes al poder ejecutivo, al legislativo y al judicial de cada orden de gobierno.

De lo anterior se concluye: la Carta Magna dicta que son obligaciones de las autoridades del orden federal, así como de las entidades federativas las de promover, respetar, proteger y garantizar los derechos de las mujeres, niñas y adolescentes, al igual que prevenir, investigar y sancionar los actos cometidos en contra de sus derechos humanos, por lo que la ejecución de todo acto de violencia contra ellas y la concreción de violencia feminicida, deben ser investigados y sancionados. De no realizarse dichas acciones, como ha ocurrido en casos resueltos por la Corte Interamericana de Derechos Humanos, el Estado incurre en irresponsabilidad.

Por su parte, la Ley General de Acceso de las Mujeres a una Vida Libre de Violencia, expresamente dispone en su artículo 40 que la Federación, las entidades federativas, el Distrito Federal (hoy Ciudad de México) y los municipios, coadyuvarán para el cumplimiento de los objetivos de esta Ley, de conformidad con las competencias previstas en el ordenamiento en cita y demás instrumentos legales aplicables. Asimismo, el artículo 38, fracción X de la citada Ley, dispone que las entidades federativas deben publicar semestralmente la información general y estadística sobre los casos de violencia contra las mujeres para integrar el Banco Nacional de Datos e Información sobre Casos de Violencia contra las Mujeres (Diario Oficial de la Federación, 2020).

$\mathrm{Al}$ respecto, es menester añadir que el pasado 16 de agosto de 2018 fue publicado en el Diario Oficial de la Federación el "Acuerdo por el que se establecen los Lineamientos para determinar e integrar la información del Banco Nacional de Datos e Información sobre Casos de Violencia contra las Mujeres" (2018), cuyo objetivo principal reside en determinar e integrar los datos personales transferidos por las autoridades integrantes del Sistema Nacional y de los Sistemas
Estatales, de la información relacionada con violencia contra las mujeres.

Por ello, un aspecto clave para la integración del referido Banco de Datos, es la información proporcionada tanto por el Sistema Nacional como por los Sistemas Estatales, de manera que la omisión de datos o incluso brindarlos de manera incompleta o sesgada, repercute en un diseño deficiente de políticas públicas.

Una vez delineado el conjunto de disposiciones que establecen el cúmulo de obligaciones que tiene el Estado - desde el nivel de gobierno federal, pasando por las entidades federativas y culminando en los municipios -, es posible dar paso al estudio del deber de coordinación en materia de seguridad pública en los mismos.

\section{Deber de coordinación en materia de seguridad pública}

De conformidad con el artículo $2^{\circ}$ de la Ley General del Sistema Nacional de Seguridad Pública, expedida el 02 de enero de 20094, la seguridad pública es una función a cargo de la Federación, las entidades federativas y los municipios, que tiene como fines: salvaguardar la integridad y derechos de las personas, preservar las libertades, el orden y la paz públicos. Por lo tanto, las obligaciones de ejecutar las medidas para lograr la consolidación de un efectivo Sistema de Seguridad Pública, compete a los tres órdenes de gobierno.

El mismo artículo de esta ley dispone que el Estado desarrollará políticas en materia de prevención social del delito con carácter integral, sobre las causas que generan la comisión de delitos y conductas antisociales, así como programas y acciones para fomentar en la sociedad valores culturales y cívicos, que induzcan el respeto a la legalidad y a la protección de las víctimas.

El artículo 7 establece que deberán coordinarse las instituciones de Seguridad Pública de la Federación, las entidades federativas y los municipios, en el ámbito de su competencia, para la formulación de políticas integrales, sistemáticas, continuas y evaluables, así como programas y estrategias en materia de seguridad pública para la ejecución, el seguimiento y

4. Ley General del Sistema Nacional de Seguridad Pública. Última reforma publicada el 27 de mayo de 2019. 
evaluación de las políticas, estrategias y acciones; así como para generar, compartir, intercambiar, ingresar, almacenar y proveer información, archivos y contenidos a las Bases de Datos que integran el Sistema Nacional de Información.

El Sistema de Seguridad Pública está integrado por diversos órganos, entre ellos, el Consejo Nacional (instancia superior de coordinación y definición de políticas públicas), los Consejos Locales e Instancias Regionales y el Secretariado Ejecutivo del Sistema, entre otros. Además, la Ley General del Sistema Nacional de Seguridad Pública prevé como obligaciones de la Federación, las entidades federativas y los municipios, suministrar, consultar y actualizar la información, que diariamente se genere sobre Seguridad Pública mediante los sistemas e instrumentos tecnológicos respectivos, al Sistema Nacional de Información (artículo 109).

Cabe destacar que el artículo 37 de la multicitada ley, dispone que los Consejos Locales y las Instancias Regionales deben organizarse de forma similar al Consejo Nacional, de modo que les sea posible actuar en un marco de coordinación y guardando los fines de la Seguridad Pública. Asimismo, para la remisión de la información requerida por el Secretariado Ejecutivo, deben asignar a uno de sus servidores públicos como enlace responsable de atender y dar seguimiento a la operación del Sistema en su respectiva entidad federativa, estando obligado a proporcionar la información requerida por el Secretariado, en un plazo razonable que no debe exceder de 30 días naturales, salvo justificación fundada.

En adición, esta ley prevé un capítulo especial con los tipos penales de los delitos cometidos contra el funcionamiento del Sistema Nacional de Información en Seguridad Pública. Así, el artículo 138 establece una sanción de 1 a 4 años de prisión, multa, destitución e inhabilitación para desempeñarse en otro empleo, puesto, cargo o comisión en cualquier orden de gobierno, a quien dolosa y reiteradamente se abstenga de proporcionar al Sistema Nacional de Información, al Secretariado Ejecutivo o al Centro Nacional de Información (CNI), la información que esté obligado, en términos de esta ley, a pesar de ser requerido por la autoridad correspondiente.

Si bien la configuración del hecho requiere la comprobación de una conducta "dolosa", que de antemano complica su aplicación, no debe pasarse por alto que la ley expresamente prevé obligaciones consistentes en brindar información para la integración del Sistema Nacional de Información en Seguridad Pública, y este deber ha de efectuarse por funcionarios públicos de los tres niveles de gobierno, e incluso, el no hacerlo contrae una sanción penal que puede conllevar pena privativa de libertad en caso de que omitan facilitar la información requerida.

En otras palabras, es posible afirmar que existe la obligación de las entidades federativas de coadyuvar en la consolidación de un Estado que promueva una vida libre de violencia contra las mujeres $y$, en consecuencia, que contribuyan a la erradicación de la violencia feminicida. Dicha obligación se traduce en la publicación semestral de información general y estadística sobre los casos de violencia contra las mujeres. Cabe añadir que el CNI del SESNSP es la instancia coordinadora de los tres órdenes de gobierno que recopila la incidencia delictiva, incluyendo el delito de feminicidio. Lo anterior es proporcionado por las fiscalías y procuradurías generales de justicia de las 32 entidades federativas a través de un formato de acopio de información denominado CNSP/38/2015, aprobado por el Consejo Nacional de Seguridad Pública.

El CNI publica cada día 20 de mes la información proporcionada relativa a la incidencia delictiva, que incluye homicidio doloso y feminicidio. Además, cada día 25 de mes se publica información de incidencia delictiva y reportes de llamadas de emergencia 9-1-1 relacionada con mujeres, dentro de la cual se incluye el feminicidio (SESNSP, 2019). Cabe señalar que la clasificación y reporte de feminicidio se realiza a través de los "Lineamientos para el reporte de feminicidio", que fue elaborado por el Secretariado Ejecutivo y la Conferencia Nacional de Procuración de Justicia, quien los publicó y distribuyó a las instituciones de Procuración de Justicia (2018).Es importante agregar que, el propio CNSP instauró en el año 2017 la práctica de que todo homicidio de mujer se investigaría con el protocolo de feminicidio y se reportaría de conformidad con los elementos probatorios que se tuvieran para su registro (Diario Oficial de la Federación, 2018) ${ }^{5}$. No

5. “Acuerdos del Consejo Nacional de Seguridad Pública, aprobados en su Cuadragésima Tercera Sesión Ordinaria, celebrada el 21 de diciembre de 2017", publicados el 06 de 
obstante, dichos delitos pueden ser actualizados y reclasificados de feminicidio a homicidio doloso de mujer y viceversa, lo cual se puede advertir con las actualizaciones que llevan a cabo las procuradurías y fiscalías de la incidencia delictiva que remiten al CNI, así como con la información del microdato que proporcionan.

En ese sentido, el CNI del SESNSP es la instancia encargada del acopio homologado de información de feminicidio y de vigilar de forma constante que la información sea enviada con calidad, oportunidad y consistencia. Para tal fin, el SESNSP implementa un proceso de revisión estadística junto con la Oficina de Naciones Unidas contra la Droga y el Delito (UNODC), en las procuradurías y fiscalías generales de justicia de las 32 entidades federativas para verificar la información.

Sin embargo, pese a que las procuradurías y fiscalías generales estatales realizan el envío de la información generada de incidencia delictiva, derivado de la autonomía de estos entes, no es posible verificar la información en las carpetas de investigación, aunado a que hasta el momento no existen datos proporcionados por la Comisión Nacional para Prevenir y Erradicar la Violencia Contra las Mujeres, instancia encargada de plantear la política en la materia.

Por lo anterior, el SESNSP se dedica únicamente a mantener publicada en su página web la incidencia delictiva y la información de violencia contra mujeres que le es proporcionada, la cual es pública y está disponible para la población, sin perjuicio de que dicha información pueda o no ser reclasificada y sin la certeza de si la misma está directamente relacionada con las medidas empleadas por cada entidad federativa, para realizar acciones tendentes a erradicar toda forma de violencia contra las mujeres y, en particular, su manifestación más grave: el feminicidio.

Es así como los argumentos vertidos permiten concluir que, tomando en consideración que el incumplimiento de dichas obligaciones se traduce en responsabilidades de carácter subjetivo (si recaen como consecuencia de un daño directamente causado y fundado en la culpa) o bien, objetivo (si son emanadas de un riesgo creado que se traduce en evento dañoso, por cuyas

febrero de 2018 consecuencias perjudiciales se está obligado a responder) (De Pina. 2012, p. 443)., existen obligaciones tanto del gobierno federal, como de las entidades federativas y de los municipios, de llevar a cabo progresivamente acciones tendentes a erradicar la violencia feminicida contra las mujeres, niñas y adolescentes, tales como 1) brindar y recabar información de calidad sobre la incidencia delictiva sistematizada, e interpretable; y 2) con esa información, diseñar políticas públicas evaluables e idóneas para combatir la violencia de género y su expresión más grave: el feminicidio. Ante el incumplimiento de dichas obligaciones, se incurre en responsabilidades de carácter objetivo, ya que su derivación es indirecta, al tener como origen un riesgo creado.

\section{CONCLUSIONES}

De una interpretación sistemática de los artículos $1^{\circ}$ y 133 constitucionales, los tratados internacionales y la legislación nacional de la materia, es posible deducir que son obligaciones de todas las autoridades del estado Mexicano, tanto federales como de las autoridades de las entidades federativas y municipales, las de promover, respetar, proteger y garantizar los derechos humanos de las mujeres, niñas y adolescentes, así como prevenir, investigar y sancionar los actos cometidos en contra del goce de sus derechos, por lo que la ejecución de todo acto de violencia contra ellas y la concreción de violencia feminicida debe ser condenada.

La Ley General del Sistema Nacional de Seguridad Pública (LGSNSP), al establecer en su artículo $2^{\circ}$ que la seguridad pública es una función a cargo de la Federación, las entidades federativas y los municipios, que tiene como fines salvaguardar la integridad y derechos de las personas, preservar las libertades, el orden y la paz públicos, entraña una obligación de ejecutar las medidas para lograr la consolidación de un efectivo Sistema de Seguridad Pública que compete a los tres órdenes de gobierno.

Por lo tanto, existe un deber de coadyuvancia y coordinación que las entidades federativas deben llevar a cabo y que se traduce, entre otras acciones, en proporcionar información para la integración de los sistemas dispuestos para recolectar los datos en materia delictiva, en este caso, en cuanto 
a estadísticas de violencia de género e incidencia delictiva.

La misma legislación prevé sanciones que incluyen pena privativa de libertad, multa y destitución a los funcionarios públicos que omitan dolosa y reiteradamente el flujo de la información que están obligados a proporcionar, en este caso, en incidencia delictiva. Dicha información es útil para definir directrices y diseñar políticas públicas pertinentes para que progresivamente la tendencia sea la erradicación de la violencia contra las mujeres y por ende, el feminicidio.

En otras palabras, es obligación de los funcionarios públicos federales y de las entidades federativas brindar información relativa tanto de la incidencia de violencia de género como particularmente en materia de feminicidio, a las instituciones encargadas de concentrarla. De igual forma, están obligados a llevar a cabo acciones y programas que tengan la finalidad de prevenir y erradicar dichas conductas social y jurídicamente reprochables. Lo ideal es, sin duda, que su diseño esté fundado en la información obtenida, con el fin de que las medidas que se empleen sean acordes con la realidad, evaluadas y evaluables. Lo anterior tiene directa repercusión en lograr que las mujeres, niñas y adolescentes de todo el territorio nacional tengan una vida libre de violencia.

Así, con base en las obligaciones en materia de derechos humanos de todas las autoridades, en todos los niveles $y$ en sus respectivos ámbitos de competencia, de prevenir y realizar progresivamente los actos tendientes a erradicar violaciones a derechos humanos, bajo el contexto de violencia generalizada y, en especial contra las mujeres, niñas y adolescentes por el que atraviesa actualmente el país, es importante determinar la responsabilidad de quienes encabezan los gobiernos en cada nivel.

Como se habrá apreciado, se está en medio de una "cadena de errores", que posiblemente tiene origen en la ineficacia normativa y no en la norma en sí. Si bien podría considerarse una deficiencia la del artículo 138 de la Ley General del Sistema Nacional de Seguridad Pública para la aplicación de la sanción respectiva, al condicionar a la comprobación del "dolo" que las y los funcionarios no proporcionen a las instancias correspondientes la información a la que estén obligados, se puede considerar que la norma aplicada proactivamente, debería constituir un parteaguas en la realización de las investigaciones que sean necesarias para corroborar el hecho. Es decir, probablemente se trate de un complejo problema sistemático-institucional, cuyo origen es la ausencia de investigación, más que de un problema meramente normativo por el que deba legislarse.

Sin embargo, dado que el propósito del presente artículo representa un primer paso: el destacar cómo el incumplimiento de estas obligaciones tristemente se traduce en postergar demandas sociales para la protección de los derechos de las mujeres, niñas y adolescentes, lo advertido anteriormente será motivo de otro estudio.

Asimismo, es cierto que el contexto atiende a un problema de carácter multifactorial, pero es inaudito que los esfuerzos empleados en lo que atañe al campo jurídico sean burlados por las autoridades ejecutivas, por lo que es menester que la ciudadanía exija su implementación para no permanecer en la inmovilidad, especialmente porque se trata de un bien jurídico tutelado a partir del cual tienen lugar todos los demás derechos humanos: la vida.

\section{BIBLIOGRAPHY}

- "Acuerdo por el que se establecen los Lineamientos para determinar e integrar la información del Banco Nacional de Datos e Información sobre Casos de Violencia contra las Mujeres". Diario Oficial de la Federación
(2018). Disponible en: http://www.dof.gob. $\mathrm{mx} /$ nota_detalle.php?codigo $=5535015 \& \mathrm{fec}$ ha $=16 / 08 / 2018$.

- "Acuerdos del Consejo Nacional deSeguridad Pública, aprobados en su Cuadragésima 
Tercera Sesión Ordinaria, celebrada el 21 de diciembre de 2017", Diario Oficial de la Federación (06 de febrero, 2018).

- Beauregard, L. P. (22 de enero, 2020) "2019 se convierte en el año más violento en la historia reciente de México". El País, Disponible en https://elpais. com/internacional / $2020 / 01 / 21 /$ mexico/1579621707_576405.html

- CNN en español (21 de enero, 2020). "Es oficial: el 2019 ha sido (sic) el año más violento". Disponible en https://cnnespanol. cnn.com/2020/01/21/es-oficial-2019-hasido-el-ano-mas-violento-en-mexico/.

- Comisión Nacional de Derechos Humanos (06 de noviembre, 2019). "Recomendación General 40/2019 Sobre la violencia feminicida y el Derecho de las Mujeres a una vida libre de violencia en México". Diario Oficial de la Federación, Disponible en https://bit.ly/2xK2g9A.

- Conferencia Nacional de Procuración de Justicia (2018). "Lineamientos para el registro y clasificación de los presuntos delitos de feminicidio para fines estadísticos", Disponible en https:// www.gob.mx/cms/uploads/attachment/ file/310369/Lineamientos_registro_ feminicidio_CNPJ_aprobada_5MZ02018. pdf.

- Constitución Política de los Estados Unidos Mexicanos (1917). Última reforma publicada en Diario Oficial de la Federación el 08 de mayo de 2020. Disponible en http:// www.diputados.gob.mx/LeyesBiblio/ pdf/1_060320.pdf. [Consultada el 20/05/2020].

- Convención Interamericana para Prevenir, Sancionar y Erradicar la Violencia Contra la Mujer "Convención De Belém Do Pará" (1994). Organización de Estados Americanos. Disponible en https://www. oas.org/juridico/spanish/tratados/a-61. html [Consultada el 15/04/2020].

- Corte IDH. Caso González y Otras ("Campo
Algodonero") Vs. México. Excepción Preliminar, Fondo, Reparaciones y Costas. Sentencia del 16 de noviembre de 2009. Serie C No. 205, pp.: 151 y ss. Disponible en https://www.corteidh.or.cr/docs/casos/ articulos/seriec_205_esp.pdf [Consultado el 05/05/2020].

- De Pina V., R. (2012). Diccionario de Derecho, México: Porrúa.

- Espino, M. (20 de enero, 2020). "Es oficial: el 2019 fue el año más violento". El Universal, Disponible en https://www. eluniversal.com.mx/nacion/seguridad/ es-oficial-2019-fue-el-ano-mas-violento.

- Fernández A., G. (2013). "Análisis sobre la responsabilidad del Estado Mexicano por los crímenes contra mujeres en Ciudad Juárez en base al asunto de la CIDH "campo algodonero", Journal of International Law. 4 (02), (julio-diciembre, 2013), pp.: 84-97. Disponible en: https:// www.upo.es / export/portal/com / bin/portal/upo/profesores/gferarr/ profesor/1392736953428_articulo_ publicado_eafit_responsabilidad_mexico. pdf. [Consultado el 05/05/2020].

- Gobierno de México (2019). Secretariado Ejecutivo del Sistema Nacional de Seguridad Pública. Disponible en https://www.gob. mx/sesnsp. [Consultado el 02/05/2020].

- Ley General de Acceso de las Mujeres a una Vida Libre de Violencia (2007). Última reforma publicada en el Diario Oficial de la Federación el 13 de abril de 2020. Disponible en: http://www.diputados.gob. $\mathrm{mx} /$ LeyesBiblio/ref/lgamvlv.htm

- Ley General del Sistema Nacional de Seguridad Pública (2009). Última reforma publicada en el Diario Oficial de la Federación el 27 de mayo de 2019. Disponible en http://www.diputados.gob. $\mathrm{mx} /$ LeyesBiblio/ref/lgsnsp.htm

- Martínez, F. (26 de enero, 2020). "2019, el más violento para las mexicanas". 
La Jornada, Disponible en https:// w w w . jornada.com.mx/ultimas / politica/2020/01/26/el-2019-el-masviolento-para-las-mexicanas-4369.html.

- ONU Mujeres (2018). Violencia y femicidio de niñas y adolescentes en México, diciembre de 2018. Disponible en https://bit. ly/2XRX6TI.

- Secretariado Ejecutivo del Sistema Nacional de Seguridad Pública. "Centro Nacional de
Información". Disponible en http://www. secretariadoejecutivo.gob. $\mathrm{mx} /$ unidadessecretariado/centro-nacional-informacion. php.

- Sistema Nacional de Seguridad Pública (2019). Información sobre violencia contra las mujeres. Información con corte al 31 de diciembre de 2019. Disponible en https:// bit.ly/2SywSSY. 